This paper is accepted for publication in the Journal of Ocean Engineering

\title{
Simplified load estimation and sizing of suction anchors for spar buoy type floating offshore wind turbines
}

Laszlo Arany ${ }^{1}$, S. Bhattacharya²

\author{
${ }^{1}$ Design Engineer, Atkins (UK) \\ ${ }^{2}$ Chair Professor in Geomechanics, University of Surrey (UK)
}

\begin{abstract}
:
Floating offshore wind turbines are complex dynamic structures, and detailed analysis of their loads require coupled aero-servo-hydro-elasto-dynamic simulations. However, time domain approach used for such analysis is slow, computationally expensive and requires detailed data about the wind turbine. Therefore, simplified approaches are necessary for feasibility studies, front-end engineering design (FEED) and the early phases of detailed design. This paper aims to provide a methodology with which the designer of the anchors can easily and quickly assess the expected ultimate loads on the foundations. For this purpose, a combination of a quasi-static wind load analysis and Morison's equation for wave load estimation using Airy waves is employed. Dynamic amplification is also considered and design load cases are established for ultimate limit state (ULS) design. A simple procedure is also presented for sizing suction caisson anchors. All steps are demonstrated through an example problem and the Hywind case study is considered for such purpose.
\end{abstract}

Keywords: Floating Wind Turbines, Anchor lines, ULS Loads, Hywind wind farm 


\subsection{Introduction:}

Offshore wind turbines are becoming significant contributors to the energy mix of many European countries, including the UK, the Netherlands, Germany and Belgium. However, the vast majority of the currently installed capacity worldwide is in shallow waters, particularly the North Sea, Irish Sea and Baltic Sea. The water depth for most currently operational wind farms is below $30-35 \mathrm{~m}$. Commercial wind turbines are almost exclusively bottom fixed structures, with the majority of them installed on monopile foundations.

Most of the wind resource worldwide, however, is found in deeper waters, including significant portions of the coasts of the US, Japan, China, Norway and the Mediterranean (Henderson et al 2002; European Wind Energy Association 2013; Ho et al 2016). Floating offshore wind turbines (FOWTs) are considered the best solution for harvesting wind energy from deep water sites where bottom fixed turbines are uneconomical (Myhr et al 2014). Analysis of loads and motions of FOWTs is a challenging task, and typically requires a coupled aero-servo-hydro-dynamic analysis. Furthermore, anchor design requires incorporating soil-structure interaction (SSI) in the analysis.

It is important to have a simplified methodology for estimating the loads on the anchors in order to generate conceptual anchor designs for feasibility studies and the early phases of design. This paper aims to provide a simplified approach for finding an upper bound limit for the expected loads on the floating offshore wind turbine structure. These loads may be transferred to the anchor through different load paths for different mooring and anchor types (Randolph and Gourvenec 2011). The load estimation methodology presented in the paper is applicable for most combinations of mooring systems and anchors, however, the anchor sizing example presented considers catenary moorings and suction caisson anchors.

As opposed to offshore oil and gas structures where vertical and horizontal loads dominate the loading, the dominant load for bottom fixed offshore wind turbines is the overturning moment. These moments usually form the design basis for both Ultimate Limit State (ULS) and Serviceability Limit State (SLS) requirements. However, in the case of floating wind turbines, the righting moment which acts against the overturning moment is provided by the floating platform (e.g. a ballast system for a spar supported wind turbine). Therefore, designing against the overturning moment is the task of the naval architect (the designer of the floating platform) and is of little concern to the designer of the foundation (anchor).

The main loads transferred to the anchoring system are the horizontal and vertical forces, see Figure 1. The horizontal force is caused by the combination of

- thrust force on the rotor due to wind - $F_{u}$,

- drag force on the wind turbine tower and the platform sections above mean sea level - $F_{D T}$,

- wave load on the spar buoy - $F_{w}$,

- current load on the spar buoy $-F_{C}$,

- rotational frequency loads such as mass and aerodynamic imbalance loads (1P loads) - $F_{1 P}$,

- blade passage frequency loads (3P loads) $-F_{3 P}$.

It has been shown by Arany et al. $(2015,2017)$ that the wind load on the rotor and the wave load on the support structure dominates the magnitude of loading on the foundation. Furthermore, the 1P, 3P, current and tower drag loads are less significant. It should be noted, however, that current loads are 
significant for estimating the motions of the platform. Simplified calculation methods are derived below to obtain the ultimate load on the anchor of a spar supported floating offshore wind turbine. An example of an offshore wind turbine supported on a floating spar is then considered based on the Hywind floating platform, currently being built in Scotland (Statoil 2015). Finally, a simplified anchor sizing procedure is presented, which is demonstrated to produce conservative upper bound estimates for the required suction caisson with similar values to those found in the environmental statement of the Hywind floating wind park (Statoil 2015).

\subsection{Methodology}

In order to analyse the Ultimate Limit State (ULS) load on the Floating Offshore Wind Turbine (FOWT) anchor, the following ultimate load scenarios are defined, using the terminology of DNVGL-ST-0437 (DNVGL 2017):

(E-1) the combination of the 50-year extreme wind speed (with the turbine shut down) and the maximum wave load due to the 50 -year extreme wave height, or

(E-2) the combination of the maximum wind load due to Extreme Operating Gust (EOG) at rated wind speed and the 1-year extreme wave height.

It is not necessary to consider the scenario with the maximum wave height (due to the 50-year extreme wave height) and the maximum wave load (due to EOG at rated wind speed) together as the probability of both occurring together is negligible for the intended design life of 25 years. This is because the maximum wind load occurs when the wind speed is around the rated wind speed and the turbine is operational, while the maximum wave load occurs in a 50-year storm when the turbine is shut down due to the high wind speed. The thrust load on the shutdown turbine is significantly reduced compared to the peak thrust force around the rated wind speed and an example is shown in Figure 2.

A further complication in the load calculation of FOWTs compared to bottom-fixed structures is the range of allowed motions of the floater itself. Motions in six degrees of freedom (surge (x), sway (y), heave ( $\mathrm{z}$ ) displacements and the pitch (y), roll (x) and yaw (z) rotations) have to be considered for floating structures. An important difference between bottom fixed and floating structures is the allowed roll or pitch angle (typically called tilt for bottom fixed structures). DNV-JS-101 (DNV 2014) suggests $0.5^{\circ}$ total allowed tilt for bottom fixed structures including accumulated rotation, while DNVJS-103 (DNV 2013) permits $7^{\circ}$ of pitch motion for FOWTs. The pitch motion of the structure introduces a relative velocity component in the wind speed experienced by the rotor, and therefore special control algorithms are required to avoid positive feedback of the motion (Nielsen et al 2006; Jonkman 2007).

The maximum load is assumed to be the sum of the wind load $F_{u}$, the drag $F_{D}$ and inertia $F_{I}$ components of the wave load $F_{w}$, the wind drag on the superstructure (structural components above still water level) $F_{D T}$, and the current load on the floating platform $F_{C}$.

$$
F_{\text {total }}=F_{u}+F_{I}+F_{D}+F_{D T}+F_{C}
$$

The loads shown here are calculated as loads at the floater padeye where the mooring lines are connected to the floater. This load is transferred through the mooring line to the anchor. Based on the mooring and anchor type, various load paths are possible. The main mooring types are

(a) catenary mooring (typical for spar platforms and semi-submersible designs),

(b) taut line mooring (currently mainly used in very deep water in offshore oil and gas applications),

(c) vertical mooring (typical for tension leg platforms).

The most important anchor types are 
(1) gravity anchors (such as box anchors and grillage and berm anchors),

(2) embedded anchors (such as suction caisson, pile and drag anchors).

Both embedded and gravity anchors have been used in different floating offshore wind turbine concepts (Principle Power 2010; edp 2012; George 2014; Myhr et al 2014). For different mooring line and anchor combinations, the spar padeye load may be reduced by:

- the weight of the suspended section of the mooring line - $W$,

- soil friction on the horizontal mooring line sections on the seabed (typical for catenary mooring lines) $-F_{f}$, and

- soil reaction forces acting on the inverse catenary forming at an embedded anchor between the anchor padeye and the seabed $-F_{r}$.

This paper focuses on spar supported floating offshore wind turbines with catenary mooring and suction caisson anchors (using the example of the Hywind concept). Therefore, all three effects act to reduce the anchor padeye loading in normal operating conditions. For this structure type, the restoring (or righting) moment $M_{r}$ necessary to resist the overturning moment is provided by the ballast system. These are shown in Figure 1.

An upper bound estimate for the ultimate load on the anchor of a spar supported FOWT can be obtained by taking the configuration where the mooring line is completely stretched and there is no part of it lying on the seabed. This is very similar to the configuration of a single taut mooring line. In this case the load is transferred directly to the anchor without the effect of soil friction on a horizontal section of the mooring line. Furthermore, in this configuration the angle of the mooring line at the seabed is also maximal, which impacts the inverse catenary shape at the anchor. This configuration is also shown in Figure 1.

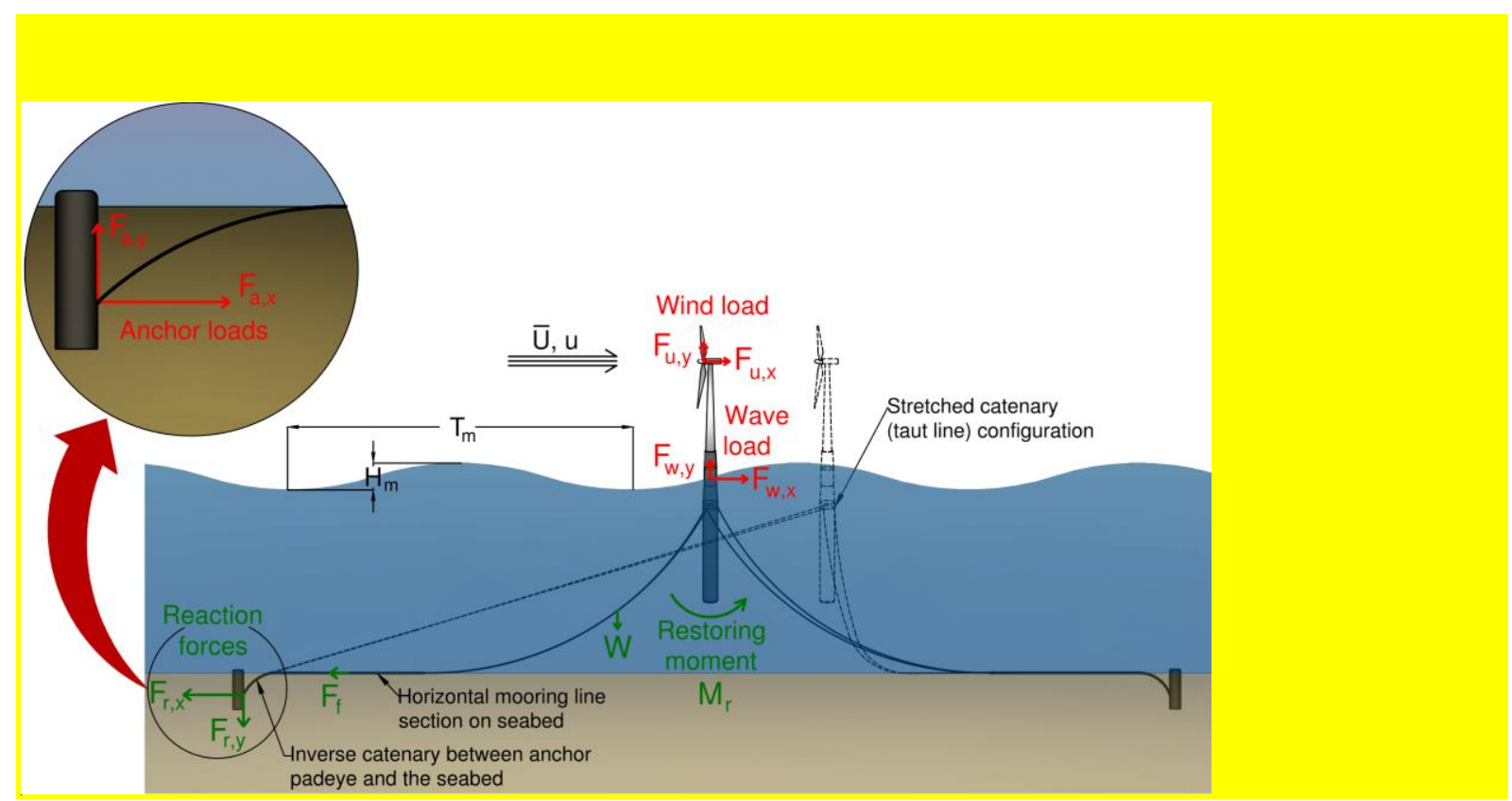

Figure 1. Normal operating conditions and stretched mooring line configurations with loads and reaction forces. Also shown are anchor loads (vertical and horizontal), mooring segments on the seabed, and inverse catenary at anchor. 
In this paper, the following methodology will be followed:

Step 1: Calculate wind load at spar padeye for both environmental load cases E-1 and E-2.

Step 2: Calculate wave load at spar padeye for both environmental load cases E-1 and E-2.

Step 3: Determine ULS load scenario as the maximum of load cases E-1 and E-2.

Step 4: Calculate the load transferred to the anchor.

The tasks are detailed in the following sections.

\subsection{Horizontal load estimation}

Current design procedure

Floating offshore wind turbine design is currently carried out following the standard DNV-OS-J103

(DNV, 2013). The standard allows for

- design by partial safety factor method,

- design assisted by testing, and

- probability-based design.

Most commonly the partial safety factor approach is chosen, which uses appropriate material factors and load factors coupling the motions of the floating platform and the wind turbine generator (WTG), that is, the rotor-nacelle-tower assembly. In this approach, the response of the platform is often determined using hydrodynamic analyses with the assumption that the WTG is a rigid a body. The obtained responses are then typically fed into a multi-body dynamics software package (e.g. DNVGL Bladed) and are used as boundary conditions at the bottom of the tower in aero-servo-elastic simulations.

The approach presented here provides an upper bound estimate for the anchor loads for preliminary and FEED design stages, using only basic data which are available at the early design phases and circumventing the need for time consuming and computationally expensive numerical analyses.

\subsubsection{Wind load on the rotor (thrust)}

From the point of view of wind load analysis, it is possible to employ a quasi-static or a coupled dynamic analysis approach. In practice, this means that the loads can be analysed such that the platform motion is neglected while calculating the wind load or by incorporating the platform motion in the load calculation. In this respect, it is important to take into account the typical natural periods of pitch and surge (or roll and sway) vibrations. Generally, FOWTs are designed such that the natural periods are above the typical wave periods. Most of the energy in a wave spectrum is in the wave period range between 3 and 25 seconds (or equivalently between 0.04 and $0.333 \mathrm{~Hz}$ ). The natural vibration periods of floating platforms are typically close to the highest natural periods in this range. These values are also well above the turbine's rotational frequency (1P), which is typically taken as the time constant of the blade pitch control. This means that if the changes in wind speed occur slowly, then the pitch control follows this change and therefore it does not register as a "sudden" change which would cause high dynamic wind load. Using this assumption, a quasi-static analysis of the wind load is possible. The thrust curve of a typical wind turbine is shown in Figure 2, which can be used to calculate the mean thrust force on the turbine. 


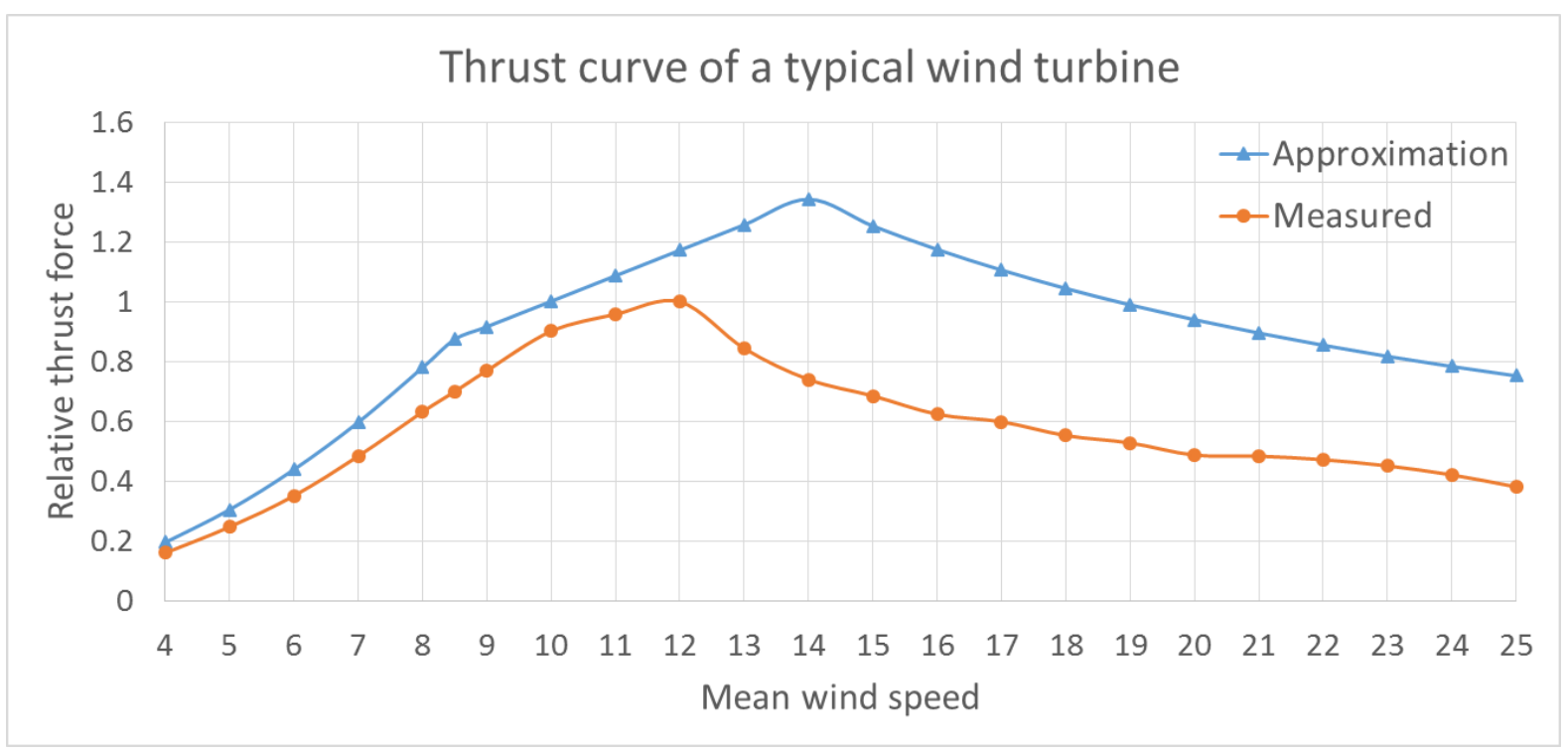

Figure 2. Thrust coefficient as a function of mean wind speed for a typical wind turbine.

A simplified way to calculate the quasi-static approximation of the wind load is assuming that the wind speed is the sum of a mean wind speed component and a turbulent wind component. The maximum wind load acts when the wind turbine is operating at the rated wind speed $U_{R}$ (or more precisely, slightly below $U_{R}$ ) where the thrust curve reaches its maximum (see Figure 2, where the rated wind speed is $14 \mathrm{~m} / \mathrm{s}$ ). The maximum wind load is then given by the scenario when the wind turbine is operating at the rated wind speed and the 50-year extreme operating gust (EOG) with wind speed magnitude $u_{E O G}$ hits the rotor, that is

$$
F_{u, E O G}=\frac{1}{2} \rho_{a} A_{R} C_{T}\left(U_{R}+u_{E O G}\right)^{2}
$$

where $\rho_{a}$ is the density of air, $A_{R}=D^{2} \pi / 4$ is the rotor swept area, $D$ is the rotor diameter, and $C_{T}$ is the thrust coefficient obtained from

$$
C_{T}=\frac{3.5\left(2 U_{R}+3.5\right)}{U_{R}^{2}}
$$

following Frohboese \& Schmuck (2010). The extreme operating gust speed $u_{E O G}$ is obtained from the formulation in DNV (2014) based on the long term distribution of 10-minutes mean wind speeds. This is expressed with the Weibull distribution, written in the cumulative distribution function (CDF) form as

$$
\Phi(\lambda, \kappa)=1-e^{-\left(\frac{U}{\lambda}\right)^{\kappa}}
$$

from which the distribution of 1-year wind speeds is given using the fact that

$$
1 \text { [year] }=365.25 \cdot 24 \cdot 6=52596[10-\text { minutes intervals }]
$$

as

$$
\Phi_{1 y r}(\lambda, s)=U(\lambda, s)^{52596}
$$

The 50-year extreme wind speed is then expressed as

$$
U_{10,50 y r}=\lambda\left[-\ln \left(1-0.98 \frac{1}{52596}\right)\right]^{\frac{1}{\kappa}}
$$

With these the 50-year extreme operating gust speed at the rated wind is expressed as

$$
u_{E O G}=\min \left\{1.35\left(U_{10,1-\text { year }}-U_{R}\right) ; \frac{3.3 \sigma_{U, c}}{1+\frac{0.1 D}{\Lambda_{1}}}\right\}
$$


where $\Lambda_{1}=L_{k} / 8.1$ is the turbulence scale parameter, $\sigma_{U, c}=0.11 U_{10,1-y e a r}$ is the characteristic standard deviation of wind speed, $U_{10,1-\text { year }}=0.8 U_{10,50-\text { year }}$ is the 1-year return period 10 -minutes mean wind speed.

During the 50-year extreme wind speed, the turbine is shut down. Therefore, the thrust load reduces to the wind drag force on the tower, blades and hub. If the wind speed is assumed to be constant with height (no wind shear) then the wind drag load in the 50-year extreme wind may be written as

$$
F_{u, U 50}=\frac{1}{2} \rho_{a}\left(3 A_{B} C_{D B}+A_{H} C_{D H}\right) U_{10,50 y r}^{2}+F_{D T}\left(U_{10,50 y r}\right)
$$

where $A_{B}, A_{H}$ are the face area of a blade and the hub, respectively; $C_{D B}, C_{D H}$ are the drag coefficient of the blade and hub, respectively; $F_{D T}$ is the drag force on the tower (given below); $\rho_{a}$ and $U_{10,50 y r}$ have been defined above.

\subsubsection{Tower drag}

The tower drag load is caused by the wind exerting a drag force on the wind turbine tower. This load is typically low in magnitude as compared to rotor thrust due to wind and compared to wave loads on the spar buoy. The vertical distribution of wind speed is given by a power law profile as

$$
U(z)=\bar{U}\left(\frac{z}{z_{h u b}}\right)^{\gamma}
$$

where $\gamma$ is the wind shear exponent, $z$ is the vertical coordinate measured from water level, $z_{h u b}$ is the hub height and $\bar{U}$ is the wind speed at hub height. The drag force on the tower can be written as

$$
F_{D}=\int_{0}^{z_{h u b}} \frac{1}{2} \rho_{a} D(z) C_{D T} U^{2}(z) d z
$$

where $D(z)$ is the vertical distribution of the tower diameter, $C_{D T}$ is the drag coefficient of the tower circular cross section, $\rho_{a}$ is the density of air. Carrying out the integration one obtains

$$
F_{D}=\frac{\rho_{a} C_{D T} \bar{U}^{2}}{2 z_{h u b}^{2 \gamma}} \int_{0}^{z_{h u b}}\left(D_{b}-\frac{D_{b}-D_{t}}{z_{h u b}} z\right) z^{2 \gamma} d z=\frac{1}{2} \rho_{a} C_{D T} \bar{U}^{2} z_{h u b} \frac{D_{b}+(2 \gamma+1) D_{t}}{(2 \gamma+1)(2 \gamma+2)}
$$

where $D_{b}$ is the tower bottom diameter, $D_{t}$ is the tower diameter at the top. Derivation of the terms given in the equations can be found in Arany et al (2017).

\subsubsection{Wave load on the spar buoy}

The wave load calculation is typically solved in four steps

(1) Obtain wave data: in this case maximum wave height $H_{m}$ and peak wave period $T_{m}$ are required. The maximum wave height and peak wave period are calculated separately for the 1-year and 50year extreme wave heights. Typically, the 50-year significant wave height $H_{S 50}$ and wave period $T_{S 50}$ are known for the site. Then the 1-year significant wave height can be obtained as

$$
H_{S 1}=0.8 H_{S 50}
$$

The maximum wave heights can be obtained from the significant wave heights as

$$
H_{m}=H_{S} \sqrt{\frac{1}{2} \ln N} \quad \text { where } \quad N=\frac{3 \text { hours }}{T_{S}}=\frac{10800[s]}{T_{s}}
$$

and $N$ is the number of waves in a 3-hour sea state. The smallest wave period for a given wave height can be obtained following DNV-RP-205 as

$$
T=11.1 \sqrt{\frac{H}{g}}
$$

where $T$ is the wave period, $H$ is the wave height and $g$ is the gravitational constant. Equations 10 and 11 can be used both for the 1-year and 50-year extreme wave heights and periods. 
(2) Choose kinematic model: here linear (Airy) wave theory is chosen as floating turbines are expected to be installed in deep water where the linear approximation is more appropriate.

$$
\begin{aligned}
& \eta=\frac{H_{m}}{2} \cos \left(-\frac{2 \pi t}{T_{m}}\right) \\
& u(z, t)=\frac{\pi H_{m} \cosh (k(S+z))}{T_{m} \sinh (k S)} \cos \left(-\frac{2 \pi t}{T_{m}}\right) \\
& \dot{u}(z, t)=\frac{2 \pi^{2} H_{m} \cosh (k(S+z))}{T_{m}^{2} \sinh (k S)} \sin \left(-\frac{2 \pi t}{T_{m}}\right)
\end{aligned}
$$

where $S$ is the water depth, $k$ is the wave number, $z$ is the vertical coordinate with $z=0$ at the stil water level, $T_{m}$ is the peak wave period, $H_{m}$ is the maximum wave height, $\eta$ is the surface elevation, $u(z, t)$ and $\dot{u}(z, t)$ are the vertical distribution of the horizontal wave particle velocity and acceleration, respectively.

(3) Choose a wave load calculation method: in this case Morison's equation is used. The force on an infinitesimal section of the spar is calculated as

$$
d F_{w}(z, t)=d F_{D}(z, t)+d F_{I}(z, t)=\frac{1}{2} \rho_{w} D_{P} C_{D} u(z, t)|u(z, t)|+C_{m} \rho_{w} A_{P} \dot{u}(z, t)
$$

where $\rho_{w}$ is the density of water, $C_{D}$ is the drag coefficient of the spar, $C_{m}$ is the inertia coefficient of the spar, $D_{P}$ is the diameter of the spar and $A_{P}=D_{P}^{2} \pi / 4$.

The total force is obtained by integrating $d F_{T}$ along the submerged length (draught) of the spar $B$

$$
F_{w}(t)=\int_{-B}^{\eta} d F_{D} d z+\int_{-B}^{\eta} d F_{I} d z=\int_{-B}^{\eta} \frac{1}{2} \rho_{w} D_{P} C_{D} u(z, t)|u(z, t)| d z+\int_{-B}^{\eta} C_{m} \rho_{w} A_{P} \dot{u}(z, t) d z
$$

The drag load is highest when the surface elevation is maximal $\eta=H_{m} / 2$, the inertia load is highest when the surface elevation is zero $\eta=0$. Therefore, the maximum drag and inertia load occur at different time instants, although calculating the maxima separately and summing them to obtain the total wave force is a conservative approach.

$$
\begin{aligned}
F_{D, \text { max }}= & \int_{-B}^{\frac{H_{m}}{2}} \frac{1}{2} \rho_{w} D_{P} C_{D} u(z, 0)|u(z, 0)| d z=\frac{1}{2} \rho_{w} D_{P} C_{D} \frac{\pi^{2} H_{m}^{2}}{T_{m}^{2} \sinh (k S)^{2}} \int_{-B}^{\frac{H_{m}}{2}} \cosh (k(S+z))^{2} d z= \\
& =\frac{1}{2} \rho_{w} D_{P} C_{D} \frac{\pi^{2} H_{m}^{2}}{T_{m}^{2} \sinh ^{2}(k S)} P_{D} \\
& P_{D}=\frac{1}{8 k}\left[e^{2 k\left(S+\frac{H_{m}}{2}\right)}-e^{-2 k\left(S+\frac{H_{m}}{2}\right)}-e^{2 k(S-B)}+e^{-2 k(S-B)}\right]+\frac{H_{m}}{4}+\frac{B}{2} \\
F_{I, \text { max }}= & \int_{-B}^{0} C_{m} \rho_{w} A_{P} \dot{u}\left(z, \frac{T_{m}}{4}\right) d z=-2 \pi^{2} C_{m} \rho_{w} A_{P} \frac{H_{m}}{T_{m}^{2} \sinh (k S)} \int_{-B}^{0} \cosh (k(S+z)) d z= \\
& =2 \pi^{2} C_{m} \rho_{w} A_{P} \frac{H_{m}}{T_{S}^{2} \sinh (k S)} P_{I} \\
& P_{I}=\frac{\sinh (k S)-\sinh (k(S-B))}{k}
\end{aligned}
$$

The wave number $k$ can be determined from the dispersion relation

$$
\omega^{2}=g k \tanh k S
$$

(4) Apply dynamic amplification factor based on the natural frequency of the structure $f_{\text {surge }}$ and damping ratio $\xi_{\text {surge }}$ for the surge mode of vibration, as well as the peak wave frequency.

$$
D A F_{\text {surge }}=\frac{1}{\sqrt{\left(1-\beta_{\text {surge }}^{2}\right)^{2}+\left(2 \zeta_{\text {surge }} \beta_{\text {surge }}\right)^{2}}} \quad \beta_{\text {surge }}=\frac{f}{f_{\text {surge }}}\left(=\frac{\text { excitation frequency }}{\text { natural frequency }}\right)
$$

It should be noted here that Response Amplitude Operators (RAOs) are often used in naval architecture instead of dynamic amplification factors. In linear analysis, the RAO expresses the structural response magnitude to a wave of unit height, for various time periods of excitation. The unit of the RAO in e.g. surge is $[\mathrm{m} / \mathrm{m}]$, that is, motion response in metres per unit wave height (1 metre). 


\subsubsection{Current load}

The simplest way to estimate the load due to currents is to assume a constant velocity $v_{C}$ profile along the spar length $L_{P}$. The force per unit length is then given by

$$
d F_{C}(z, t)=d F_{D, C}(z, t)=\frac{1}{2} \rho_{w} D_{P} C_{D P} v_{C}\left|v_{C}\right|
$$

where $C_{D}$ is the drag coefficient of the spar. The total force is obtained as

$$
F_{C}=\int_{-B}^{0} d F_{D} d z=\frac{1}{2} \rho_{w} D_{P} C_{D P} v_{C}^{2} B
$$

The constant velocity of the current is the sum of the tidal current velocity, the storm surge and the wind induced current. The wind induced component may be taken as 1.6-3.3\% of the mean wind speed following DNVGL-ST-0437 (DNV GL 2016). Typically, maximum 50-year current speeds are in the order of $1-5 \mathrm{~m} / \mathrm{s}$ and in this paper $\mathrm{v}_{\mathrm{C}} \approx 0.05 \overline{\mathrm{U}} \approx 2[\mathrm{~m} / \mathrm{s}]$ is used as a conservative estimate.

\subsection{Worked example}

A worked example presented here basically emulates the Hywind Pilot Park close to Peterhead in Scotland. Five 6MW turbines are planned on a spar buoy platform, utilizing suction caisson anchors. Provisional data (Statoil 2015) is presented in Table 1. The wind and wave loads are calculated following Section 2.

\subsection{Wind Load}

Weibull distribution for long term is given in Equation 3 with parameters in Table 1, which gives the 50year and 1 year return period 10-minutes mean wind speeds as

$$
U_{10,50 y r}=35.7\left[\frac{\mathrm{m}}{\mathrm{s}}\right] \quad U_{10,1 y r}=28.6\left[\frac{\mathrm{m}}{\mathrm{s}}\right]
$$

The Extreme Operating Gust (EOG) wind speed is calculated as

$$
u_{E O G}=7.6\left[\frac{\mathrm{m}}{\mathrm{s}}\right]
$$

and wind load due to the EOG at the rated wind speed is

$$
F_{u, E O G}=2.9[\mathrm{MN}]
$$

The wind load on the shut down structure in the 50-year extreme wind speed is

$$
F_{u, U 50}=0.72[M N]
$$

of which the the tower drag load and rotor drag load components are

$$
F_{D T}=0.18[M N] \quad F_{D T, 50 y r}=0.54[M N]
$$

The drag force on the tower at the rated wind speed is $F_{D T, U_{R}}=0.02[M N]$. 
Table 1. Parameters of the floating offshore wind turbine and the site.

\begin{tabular}{|c|c|c|c|}
\hline Parameter & Symbol & Value & Unit \\
\hline \multicolumn{4}{|c|}{ Turbine parameters } \\
\hline Rotor diameter & $D$ & 154 & $\mathrm{~m}$ \\
\hline Rated wind speed & $U_{R}$ & 12 & $\mathrm{~m} / \mathrm{s}$ \\
\hline Mass of the rotor-nacelle assembly & $m_{R N A}$ & 403 & tons \\
\hline Mass of the tower & $m_{T}$ & 626 & tons \\
\hline Drag coefficient of tower & $C_{D T}$ & 0.5 & {$[-]$} \\
\hline Tower bottom diameter & $D_{b}$ & 6.5 & $\mathrm{~m}$ \\
\hline Tower top diameter & $D_{t}$ & 4.1 & $\mathrm{~m}$ \\
\hline Hub height above sea level & $Z_{h u b}$ & 100 & $\mathrm{~m}$ \\
\hline \multicolumn{4}{|c|}{ Spar and mooring parameters } \\
\hline Spar diameter & $D_{S}$ & $14.4 / 9.5^{*}$ & $\mathrm{~m}$ \\
\hline Spar draft (depth below sea level) & $B$ & 85 & $\mathrm{~m}$ \\
\hline Mass of the ballast & $m_{B}$ & 8000 & tons \\
\hline Mass of the spar buoy & $m_{S}$ & $1700-2500$ & tons \\
\hline Centre of buoyancy below sea level & $Z_{B}$ & 50 & $\mathrm{~m}$ \\
\hline Mooring radius & $r_{m}$ & $600-1200$ & $m$ \\
\hline Unit weight of mooring chains & $\mu_{C}$ & $200-550$ & $\mathrm{~kg} / \mathrm{m}$ \\
\hline Mass of the mooring cables & $m_{C}$ & $120-660$ & tons \\
\hline \multicolumn{4}{|c|}{ Wind parameters } \\
\hline Mean wind speed at the site & $\kappa$ & 1.8 & {$[-]$} \\
\hline Weibull distribution shape parameter & $\lambda$ & 8 & $\mathrm{~m} / \mathrm{s}$ \\
\hline Wind profile exponent & $\gamma$ & $1 / 7$ & {$[-]$} \\
\hline Integral length scale & $L_{k}$ & 340.2 & $\mathrm{~m}$ \\
\hline Turbulence Intensity & $I_{15}$ & 20 & $\%$ \\
\hline \multicolumn{4}{|c|}{ Wave parameters } \\
\hline Water depth & $S$ & $95-\underline{120}$ & $\mathrm{~m}$ \\
\hline Significant wave height & $H_{S}$ & 10 & $\mathrm{~m}$ \\
\hline Peak wave period & $T_{S}$ & 11.2 & $\mathrm{~s}$ \\
\hline Density of sea water & $\rho_{w}$ & 1030 & $\mathrm{~kg} / \mathrm{m}^{3}$ \\
\hline \multicolumn{4}{|c|}{ Soil parameters } \\
\hline Soil type & \multicolumn{3}{|c|}{ Medium sand } \\
\hline Mooring chain friction on sand & $\mu$ & 0.25 & {$[-]$} \\
\hline Internal angle of friction & $\phi^{\prime}$ & 30 & $\circ$ \\
\hline Submerged unit weight & $\gamma^{\prime}$ & 9 & $\mathrm{kN} / \mathrm{m}^{3}$ \\
\hline
\end{tabular}

\subsection{Wave and Current Loads}

These loads are calculated by breaking up the spar into three sections as specified in Table 1 . The bottom $58 \mathrm{~m}$ is modelled with a diameter of $14.4 \mathrm{~m}$, the $15 \mathrm{~m}$ long coned sections is modelled with the average diameter of $11.95 \mathrm{~m}$, and the top section with a diameter of $9.5 \mathrm{~m}$. This section can be modelled using an equivalent diameters of $D_{D}=11.33 \mathrm{~m}$ for drag load calculations, and $D_{I}=12.89 \mathrm{~m}$ for inertia load calculations.

The maximum of the drag load for the 50-year Extreme Wave Height is

$$
F_{D, \max , 50 y r}=3.56[M N]
$$


and the maximum of the 50-year inertia load is

$$
F_{I, \max , 50 y r}=20.04[\mathrm{MN}]
$$

The peak loads occur at different time instants, therefore the 50-year extreme wave load is taken as

$$
F_{W, 50 y r} \approx 20.1[M N]
$$

For the 1-year Extreme Wave Height scenario the maximum of the drag load and inertia load are calculated as

$$
F_{D, \max , 1 y r}=2.2[\mathrm{MN}] \quad F_{I, \max , 50 y r}=16.67[\mathrm{MN}]
$$

The total wave load is then

$$
F_{w, 1 y r} \approx 16.7[M N]
$$

The current load is calculated as

$$
F_{C}=\frac{1}{2} \rho_{w} D_{P} C_{D P} v_{C}^{2} B \approx 2.32[M N]
$$

\subsection{Anchor load combinations}

The loads under the combined actions of wind and waves have to be considered. The two combinations of loads (E-1) and (E-2) are calculated as

$$
\begin{aligned}
& F_{E-1}=20.1+0.72+2.32 \approx 23.1[M N] \\
& F_{E-2}=16.7+2.9+2.32 \approx 21.9[M N]
\end{aligned}
$$

As expected, the wave load dominates, and the scenario with the combination of the 50-year Extreme Wave Height and the 50-year extreme mean wind speed combination produces the ULS load. It should be noted here that this load is conservative for anchor design, as the load that acts on the anchor is reduced by the weight of the suspended section of the mooring line, the friction on the horizontal section (Touch Down Zone) of the mooring line, the soil reaction on the inverse catenary shaped forerunner in the soil and the weight of the forerunner. The vertical load acts on the spar at the instant when the surface elevation at the spar is at its highest point (wave crest), while the horizontal load is dominated by the inertia load, which is highest when the surface elevation is at the mean water level. Therefore, the ultimate load is taken as the horizontal load as calculated above.

\subsection{Sizing the anchor}

In this section, a simple anchor sizing exercise is carried out assuming a suction caisson anchor. The diameter of the caisson $D$ and the embedment depth $L$ are the two main independent parameters that govern the holding capacity of the caisson for a given soil profile. Formulations for both clayey and sandy soils are given in this section. At the Hywind site, the top layer of the seabed soil is dominated by loose to medium sand. The sub-seabed soil within the embedment range of the anchor is dominantly soft clay with intermittent sand layers. In the worked example, three soil types are considered:

(1) Clay with constant undrained shear strength with depth, using an average value of $s_{u}=30 \mathrm{kPa}$

(2) Clay with linearly increasing undrained shear strength with depth, using $s_{u 0}=15 \mathrm{kPa}$ and $\frac{d s_{u}}{d z}=2 \mathrm{kPa} / \mathrm{m}$.

(3) Soft/medium sand with angle of internal friction of $\phi=30^{\circ}$ and effective unit weight of $\gamma^{\prime}=$ $9\left[\frac{k N}{m^{3}}\right]$ 
The holding capacity of suction caissons is typically determined in terms of an envelope based on the horizontal and vertical load components at the anchor. Following Randolph and Gourvenec (2011) and Supachawarote et al (2004), the envelope is given as:

$$
F P=\left(\frac{H_{u}}{H_{m}}\right)^{a}+\left(\frac{V_{u}}{V_{m}}\right)^{b}<1
$$

where

$$
a=\frac{L}{D}+0.5 \quad b=\frac{L}{3 D}+4.5
$$

An alternative formulation by Senders and Kay (2002) replaces $a$ and $b$ with $k=3$. In equation $40, \mathrm{H}_{\mathrm{m}}$ is the horizontal capacity and $V_{m}$ is the vertical capacity. On the other hand, $H_{u}$ and $V_{u}$ are the applied load. FP is the failure criterion and the maximum value can be 1 (limiting condition).

\subsubsection{Suction caisson bearing capacity in clay}

The horizontal capacity $H_{m}$ in clay is given following Randolph and Gourvenec (2011) as

$$
H_{m}=L D_{e} N_{p} \bar{s}_{u}
$$

where

$L \quad$ penetration depth of the caisson,

$D_{e} \quad$ external caisson diameter,

$N_{p} \quad$ lateral bearing capacity factor (shown to depend only slightly on $L / D_{e}$ in Randolph and Gourvenec (2011)), approximate values are given in Table 2.

$\bar{s}_{u} \quad$ average undrained shear strength over the embedded length of the caisson.

Table 2. Lateral bearing capacity factor for clays with various strength profiles.

\begin{tabular}{|l|c|c|}
\hline$N_{p}$ & $\begin{array}{c}\text { Linearly increasing } s_{u} \\
\text { with depth }\end{array}$ & Uniform $s_{u}$ with depth \\
\hline Horizontal translation & $\sim 10.5$ & $\sim 10$ \\
\hline Horizontal load at mudline & $\sim 2.5$ & $\sim 4$ \\
\hline
\end{tabular}

The three formulations for the vertical capacity represent three failure modes: (1) presence of passive suction and reverse end bearing, (2) no passive suction, caisson pullout, (3) no passive suction, caisson and soil plug pullout (internal soil plug failure). Figure 3 shows the three failure modes and the formulations are as follows:

$V_{m 1}=$ submerged weight of the caisson + external friction + reverse end bearing

$V_{m 2}=$ submerged weight of the caisson + external friction + internal friction

$V_{m 3}=$ submerged weight of the caisson + external friction + weight of the soil plug 
I. Reverse end bearing with passive suction

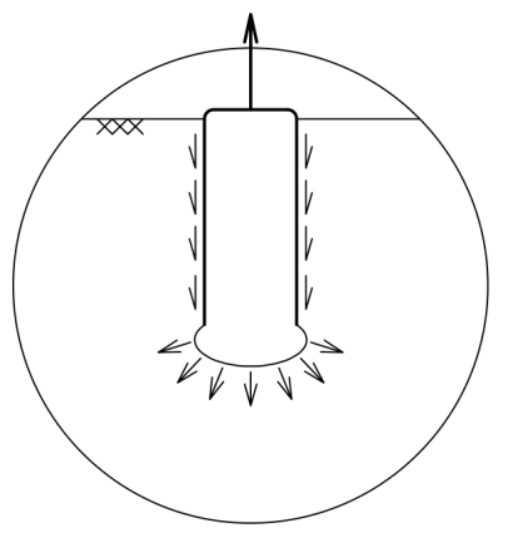

II. Reverse end bearing without passive suction, caisson only pullout

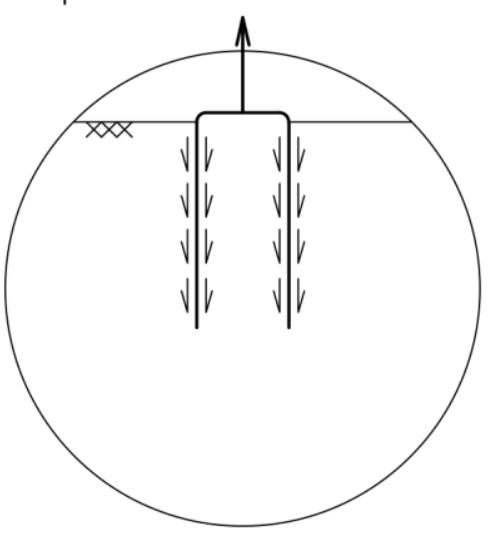

III. Reverse end bearing without passive suction, caisson and soil plug pullout

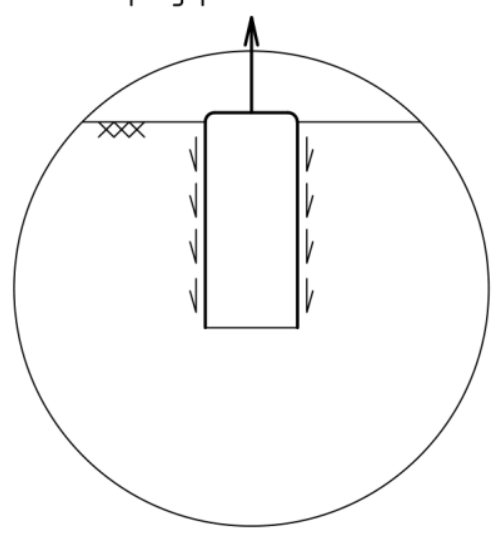

Figure 3. Pull-out failure modes of suction caissons.

Using the formulations of Randolph and Gourvenec (2011):

$$
\begin{aligned}
& V_{m 1}=W^{\prime}+A_{s e} \alpha_{e} \bar{s}_{u}+N_{c} s_{u} A_{e} \\
& V_{m 2}=W^{\prime}+A_{s e} \alpha_{e} \bar{s}_{u}+A_{s i} \alpha_{i} \bar{s}_{u} \\
& V_{m 3}=W^{\prime}+A_{s e} \alpha_{e} \bar{s}_{u}+W_{\text {plug }}^{\prime}
\end{aligned}
$$

where

$A_{\text {se }} \quad$ external shaft surface area $\approx D_{e} \pi \times L$,

$A_{s i} \quad$ internal shaft surface area $\approx D_{i} \pi \times L$,

$A_{e} \quad$ external cross-sectional area $=D_{e}^{2} \pi / 4$,

$\alpha_{e} \quad$ coefficient of external shaft friction between steel and soil,

$\alpha_{i} \quad$ coefficient of internal shaft friction between steel and soil,

$N_{c} \quad$ reverse end bearing factor ( $\left.\sim 9\right)$,

$s_{u} \quad$ representative undrained soil shear strength at caisson tip level,

$\bar{s}_{u} \quad$ average undrained soil shear strength over penetrated depth,

$W^{\prime} \quad$ submerged caisson weight,

$W_{\text {plug }}^{\prime} \quad$ effective weight of the soil plug.

\subsubsection{Suction caisson bearing capacity in sand}

The lateral capacity in sand can be calculated following

$$
H_{m, \text { sand }}=-L Q_{a v}=0.5 A_{b} N_{q} \gamma^{\prime} L^{2}
$$

where the average soil strength may be determined following Miedema et al (2007)as

$$
L Q_{a v}=D_{e} N_{q} \int_{0}^{L} \gamma^{\prime} z d z=\frac{1}{2} D_{e} N_{q} \gamma^{\prime} L^{2}
$$

where

$$
\begin{array}{ll}
\gamma^{\prime} & \text { submerged unit weight of the soil, } \\
N_{q} & \text { bearing capacity factor, calculated based on DNV Classification Note } 30.4 \text { (DNV 1992) as } \\
N_{q}=e^{\pi \tan \phi} \tan ^{2}\left(45^{\circ}+\frac{\phi}{2}\right)
\end{array}
$$


with $\phi$ being the internal angle of friction of the soil.

The vertical capacity in sand accounting for the effects of stress enhancement can be calculated following Houlsby et al (2005a); Houlsby et al (2005b) as

$$
V_{m, \text { sand }}=W^{\prime}+\gamma^{\prime} Z_{e}^{2} y\left(\frac{h}{z_{e}}\right)(K \tan \delta)_{e}\left(\pi D_{e}\right)+\gamma^{\prime} Z_{i}^{2} y\left(\frac{h}{z_{i}}\right)(K \tan \delta)_{i}\left(\pi D_{i}\right)
$$

where

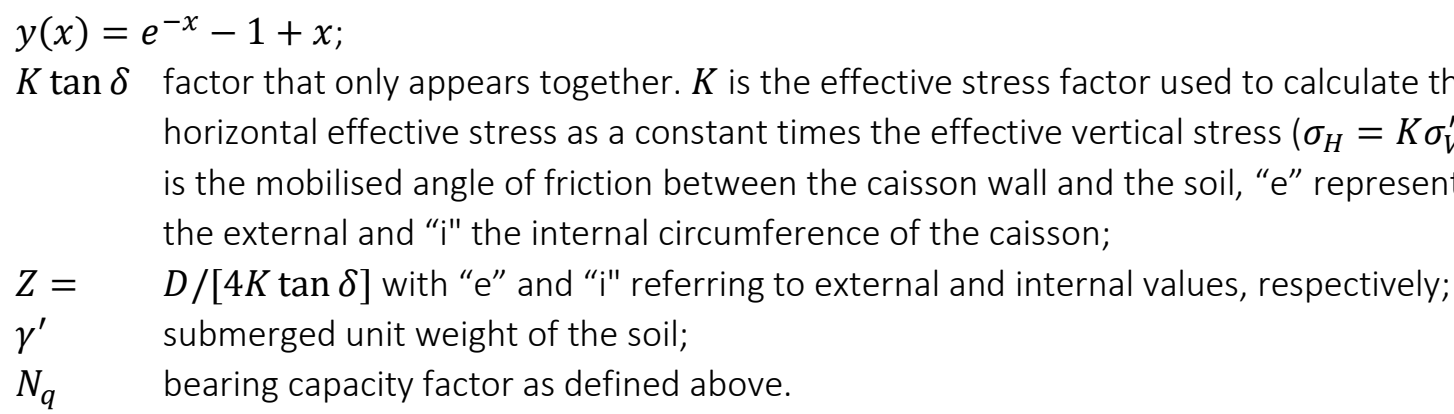

\subsubsection{Load transfer from the mudline to the anchor}

The actual load on the anchor is obtained by taking into account the load reduction on the inverse catenary forming at the anchor. This is important as not only the magnitude but the angle at which the load is applied also changes through the inverse catenary shape at the anchor. The anchor padeye tension $T_{a}$ and angle $\theta_{a}$ can be determined by simultaneously solving the following two equations following Randolph and Neubecker (1995), see Figure 4 for definition of the terms:

$$
\begin{aligned}
& \frac{T_{a}}{2}\left(\theta_{a}^{2}-\theta_{m}^{2}\right)=z_{a} Q_{a v} \\
& \frac{T_{m}}{T_{a}}=e^{\mu\left(\theta_{a}-\theta_{m}\right)} \\
& \text { where } \\
& T_{a} \quad \text { tension at the anchor padeye, } \\
& T_{m} \quad \text { tension at the mudline, } \\
& \theta_{a} \quad \text { angle of the tension at the anchor padeye to horizontal, } \\
& \theta_{m} \quad \text { angle of the tension at the mudline to horizontal, } \\
& z_{a} \quad \text { depth of the anchor padeye below mudline, } \\
& \mu \quad \text { friction coefficient between the forerunner (chain, rope or wire) and the soil, } \\
& Q_{a v} \quad \text { average soil resistance between the mudline and the padeye. }
\end{aligned}
$$




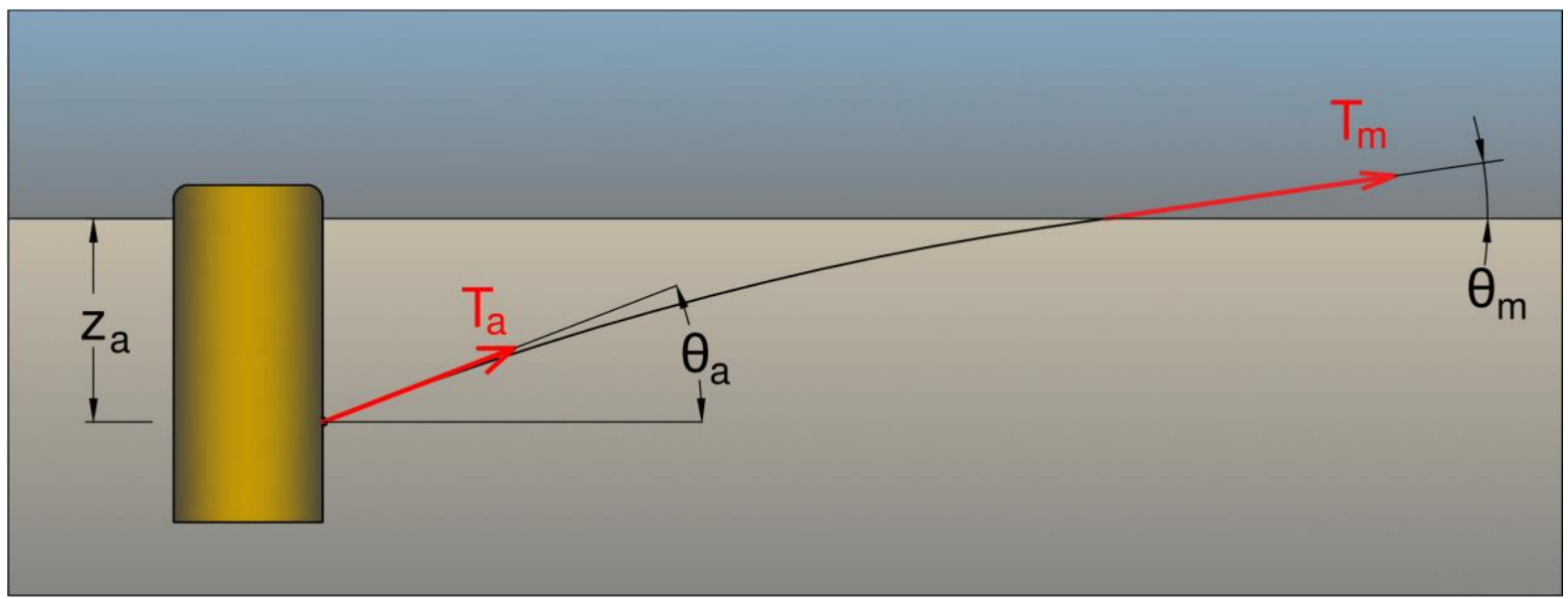

Figure 4: Loads on the anchor lines

The average soil resistance can be determined for clay as

$$
z_{a} Q_{a v}=A_{b} N_{c} \int_{0}^{z_{a}} s_{u}(z) d z
$$

where

$A_{b} \quad$ effective unit bearing area of the forerunner (equals the diameter of the rope or wire, and 2.5-2.6 times the bar diameter for a chain),

$N_{c} \quad$ bearing capacity factor (between 9 and 14 based on DNVGL-RP-E301 Design and installation of fluke anchors (DNV GL 2017)).

$s_{u}(z) \quad$ distribution of the undrained shear strength with depth.

For sand, the average soil resistance is calculated following Miedema et al (2007) as

$$
z_{a} Q_{a v}=A_{b} N_{c} \int_{0}^{z_{a}} \gamma^{\prime} z d z
$$

\subsubsection{Required caisson dimensions}

The required dimensions of the suction caisson necessary to anchor the floating platform are calculated using the ultimate load and the equations of Sections 3.4.1-3.4.3. The caisson dimensions are determined for the three different soil types given in Section 3.4, including clay with constant undrained shear strength $\left(s_{u}\right)$, clay with linearly increasing $s_{u}$ and medium dense sand.

The anchor padeye is placed at $z_{a}$ depth below mudline. This depth is determined based on moment balance such that soil resistance is mobilised due to horizontal translation of the anchor rather than rigid body rotation, see Randolph and Gourvenec (2011) and Figure 5. For sand, where strength increases linearly from zero at the mudline, this depth is $z_{a} / L=2 / 3$. For clay, the value varies between about $z_{a}=1 / 2$ and $z_{a}=2 / 3$. 


\section{Rigid body rotation}

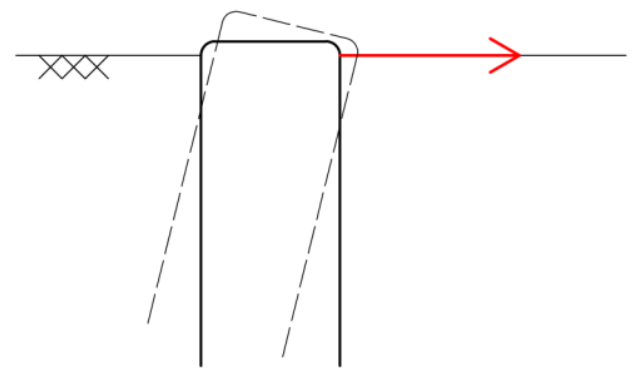

\section{Horizontal translation}

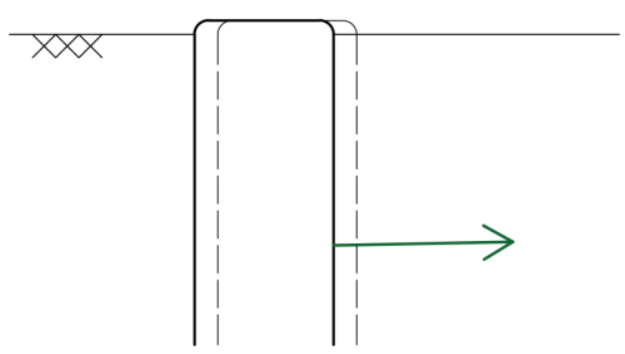

Figure 5. Failure modes of caissons under horizontal loading.

Several values of the length to diameter ratio $L / D$ are chosen for the analysis, and the required parameters are determined for each. This is carried out by the following procedure:

(1) An initial value $D_{0}$ of the caisson diameter is chosen.

(2) The embedment depth of the caisson is calculated for the chosen length to diameter ratio.

(3) The padeye depth is calculated from moment balance as described above as a portion of the embedment length.

(4) The padeye tension $T_{a}$ and forerunner angle $\theta_{a}$ are calculated using the soil data, the padeye depth and Equations 50 and 51.

(5) The horizontal and vertical force components are calculated from $T_{a}$ and $\theta_{a}$.

(6) The wall thickness is simplistically estimated using a wall thickness to diameter ratio of 70. A sensitivity study showed that this has very limited effect as it only affects the internal diameter of the caisson used for calculating the internal friction and the weight of the caisson. By changing the value from 70 to 40 or 100 the required caisson diameter changes by less than $0.1 \mathrm{~m}$.

(7) The weight of the caisson and the horizontal and vertical capacities are calculated.

(8) Equation 40 is used as failure criterion.

(9) The process is repeated until the smallest diameter is found which satisfies the failure criterion.

Table 3-5 present the results of this analysis for soft clay with constant $s_{u}$, soft clay with linearly increasing $s_{u}$ and medium dense sand, respectively. The actual Hywind project uses a length to diameter ratio of 3.2 with a caisson diameter of $5 \mathrm{~m}$ and an embedded length of $16 \mathrm{~m}$.

The dimensions determined for the length to diameter ratio of 3.2 are as follows. For soft clay with constant undrained shear strength of $s_{u}=30 \mathrm{kPa}$ the calculated diameter is identical to the actual dimensions $(D=5 \mathrm{~m}, L=16 \mathrm{~m})$. For soft clay with undrained shear strength profile given by $s_{u}(z)=$ $15 \mathrm{kPa}+2 \frac{\mathrm{kPa}}{\mathrm{m}} \cdot z$, the dimensions are determined as $(D=5.25 \mathrm{~m}, L=16.8 \mathrm{~m})$. For the medium sand, the dimensions are higher at $(D=6.9 \mathrm{~m}, L=22.1 \mathrm{~m})$.

The dimensions approximate the actual anchors very well, however, applying load factors would increase the required dimensions given by this methodology. 
Table 3. Minimum caisson dimensions for various length to diameter ratios - soft clay with constant $s_{u}$ with depth.

\begin{tabular}{|c|c|c|c|c|c|c|c|c|c|c|c|}
\hline Length-to-diameter ratio of caisson & Lc/De & 3.2 & 2 & 2.5 & 3 & 3.5 & 4 & 4.5 & 5 & 5.5 & 6 \\
\hline Minimum required caisson diameter for $L / D$ [m] & $D_{\min }$ & 5.00 & 6.35 & 5.65 & 5.20 & 4.80 & 4.50 & 4.25 & 4.05 & 3.85 & 3.70 \\
\hline Corresponding length [m] & $\mathrm{L}_{\min }$ & 16.0 & 12.7 & 14.1 & 15.6 & 16.8 & 18.0 & 19.1 & 20.3 & 21.2 & 22.2 \\
\hline Wall thickness [m] & $t_{w}$ & 0.05 & 0.063 & 0.056 & 0.052 & 0.048 & 0.045 & 0.042 & 0.04 & 0.038 & 0.037 \\
\hline Average shear strength of the soil [kPa] & Savg & 30.0 & 30.0 & 30.0 & 30.0 & 30.0 & 30.0 & 30.0 & 30.0 & 30.0 & 30.0 \\
\hline Shear strength of soil at caisson tip [kPa] & $\mathrm{Su}$ & 30.0 & 30.0 & 30.0 & 30.0 & 30.0 & 30.0 & 30.0 & 30.0 & 30.0 & 30.0 \\
\hline Submerged weight of the caisson [kN] & $W_{c}$ & 893 & 1183 & 1032 & 927 & 849 & 788 & 740 & 701 & 669 & 642 \\
\hline Submerged weight of the soil plug [kN] & $W_{p}$ & 2697 & 3422 & 3054 & 2785 & 2579 & 2416 & 2283 & 2174 & 2082 & 2005 \\
\hline External shaft friction $[\mathrm{kN}]$ & $\mathrm{Fe}_{\mathrm{e}}$ & 4878 & 4889 & 4881 & 4878 & 4879 & 4883 & 4891 & 4903 & 4918 & 4938 \\
\hline Internal shaft friction $[\mathrm{kN}]$ & $\mathrm{F}_{\mathrm{i}}$ & 4781 & 4791 & 4784 & 4781 & 4781 & 4786 & 4793 & 4805 & 4820 & 4839 \\
\hline Reverse end bearing [kN] & Freb & 4104 & 6581 & 5257 & 4378 & 3753 & 3287 & 2926 & 2640 & 2407 & 2216 \\
\hline Maximum vertical load - Mode I [kN] & $V_{1}$ & 9875 & 12654 & 11170 & 10183 & 9481 & 8959 & 8558 & 8244 & 7994 & 7795 \\
\hline Maximum vertical load - Mode II [kN] & $\mathrm{V}_{\mathrm{II}}$ & 10552 & 10864 & 10697 & 10586 & 10509 & 10457 & 10425 & 10408 & 10406 & 10418 \\
\hline Maximum vertical load - Mode III [kN] & $V_{\text {III }}$ & 8468 & 9495 & 8967 & 8590 & 8307 & 8087 & 7914 & 7777 & 7669 & 7585 \\
\hline Maximum vertical load capacity [kN] & $V_{\max }$ & 8468 & 9495 & 8967 & 8590 & 8307 & 8087 & 7914 & 7777 & 7669 & 7585 \\
\hline Maximum horizontal load capacity [kN] & $\mathrm{H}_{\max }$ & 21500 & 21548 & 21514 & 21500 & 21503 & 21523 & 21557 & 21608 & 21676 & 21762 \\
\hline Anchor padeye depth & $\mathrm{z}_{\mathrm{a}}$ & 7.98 & 6.32 & 7.06 & 7.73 & 8.35 & 8.93 & 9.48 & 10.00 & 10.51 & 11.00 \\
\hline Padeye location [\%] & $r_{z}$ & 0.500 & 0.500 & 0.500 & 0.500 & 0.500 & 0.500 & 0.500 & 0.500 & 0.500 & 0.500 \\
\hline Angle at the padeye [deg] & $\theta_{a}$ & 14.79 & 13.11 & 13.88 & 14.54 & 15.13 & 15.67 & 16.16 & 16.62 & 17.05 & 17.46 \\
\hline Tension at the padeye (variable) $[\mathrm{kN}]$ & $\mathrm{T}_{\mathrm{a}}$ & 21657 & 21816 & 21743 & 21680 & 21624 & 21574 & 21527 & 21484 & 21444 & 21406 \\
\hline Horizontal load on the anchor $[\mathrm{kN}]$ & $\mathrm{H}_{\mathrm{a}}$ & 20940 & 21248 & 21109 & 20985 & 20874 & 20772 & 20677 & 20587 & 20502 & 20420 \\
\hline Vertical load on the anchor [kN] & $V_{a}$ & 5527 & 4947 & 5214 & 5443 & 5645 & 5826 & 5991 & 6144 & 6287 & 6421 \\
\hline Horizontal load check exponent [-] & $\mathrm{a}$ & 3.7 & 2.5 & 3 & 3.5 & 4 & 4.5 & 5 & 5.5 & 6 & 6.5 \\
\hline Vertical load check exponent [-] & $\mathrm{b}$ & 5.57 & 5.17 & 5.33 & 5.50 & 5.67 & 5.83 & 6.00 & 6.17 & 6.33 & 6.50 \\
\hline Horizontal utilisation [-] & $\mathrm{V}_{\mathrm{a}} / \mathrm{V}_{\max }$ & 0.653 & 0.521 & 0.581 & 0.634 & 0.68 & 0.72 & 0.757 & 0.79 & 0.82 & 0.847 \\
\hline Vertical utilisation [-] & $\mathrm{H}_{\mathrm{a}} / \mathrm{H}_{\max }$ & 0.974 & 0.986 & 0.981 & 0.976 & 0.971 & 0.965 & 0.959 & 0.953 & 0.946 & 0.938 \\
\hline
\end{tabular}


Table 4. Minimum caisson dimensions for various length to diameter ratios - soft clay with linearly increasing $s_{u}$ with depth.

\begin{tabular}{|c|c|c|c|c|c|c|c|c|c|c|c|}
\hline Length-to-diameter ratio of caisson [-] & $\mathrm{Lc} / \mathrm{De}$ & 3.2 & 2 & 2.5 & 3 & 3.5 & 4 & 4.5 & 5 & 5.5 & 6 \\
\hline Minimum required caisson diameter $[\mathrm{m}]$ & $D_{\min }$ & 5.25 & 6.90 & 6.05 & 5.45 & 4.95 & 4.60 & 4.25 & 4.00 & 3.80 & 3.60 \\
\hline Corresponding length [m] & $L_{\min }$ & 16.8 & 13.8 & 15.1 & 16.4 & 17.3 & 18.4 & 19.1 & 20.0 & 20.9 & 21.6 \\
\hline Wall thickness [m] & $t_{w}$ & 0.052 & 0.069 & 0.06 & 0.054 & 0.049 & 0.046 & 0.042 & 0.04 & 0.038 & 0.036 \\
\hline Average shear strength of the soil [kPa] & Savg & 27.48 & 25.31 & 26.29 & 27.16 & 27.94 & 28.67 & 29.34 & 29.98 & 30.59 & 31.18 \\
\hline Shear strength of soil at caisson tip [kPa] & Su & 39.96 & 35.62 & 37.58 & 39.32 & 40.89 & 42.33 & 43.68 & 44.96 & 46.18 & 47.36 \\
\hline Submerged weight of the caisson [kN] & $W_{c}$ & 1012 & 1524 & 1253 & 1069 & 937 & 838 & 760 & 698 & 647 & 606 \\
\hline Submerged weight of the soil plug [kN] & $W_{p}$ & 3055 & 4410 & 3706 & 3213 & 2848 & 2567 & 2344 & 2164 & 2016 & 1894 \\
\hline External shaft friction $[\mathrm{kN}]$ & $\mathrm{Fe}_{\mathrm{e}}$ & 4856 & 4884 & 4867 & 4858 & 4855 & 4858 & 4868 & 4885 & 4908 & 4941 \\
\hline Internal shaft friction [kN] & $\mathrm{F}_{\mathrm{i}}$ & 4759 & 4786 & 4770 & 4761 & 4758 & 4761 & 4771 & 4787 & 4810 & 4842 \\
\hline Reverse end bearing [kN] & $\mathrm{F}_{\text {reb }}$ & 5941 & 9253 & 7493 & 6312 & 5465 & 4829 & 4336 & 3944 & 3627 & 3367 \\
\hline Maximum vertical load - Mode $1[\mathrm{kN}]$ & $\mathrm{V}_{\mathrm{m} 1}$ & 11809 & 15661 & 13613 & 12239 & 11257 & 10525 & 9964 & 9527 & 9183 & 8914 \\
\hline Maximum vertical load - Mode 2 [kN] & $\mathrm{V}_{\mathrm{m} 2}$ & 10627 & 11195 & 10890 & 10688 & 10550 & 10457 & 10399 & 10369 & 10366 & 10388 \\
\hline Maximum vertical load - Mode $3[\mathrm{kN}]$ & $V_{m 3}$ & 8923 & 10818 & 9827 & 9141 & 8641 & 8263 & 7972 & 7746 & 7572 & 7441 \\
\hline Maximum vertical load capacity [kN] & $\mathrm{V}_{\mathrm{m}}$ & 8923 & 10818 & 9827 & 9141 & 8641 & 8263 & 7972 & 7746 & 7572 & 7441 \\
\hline Maximum horizontal load capacity [kN] & $\mathrm{H}_{\mathrm{m}}$ & 21403 & 21526 & 21453 & 21411 & 21398 & 21413 & 21455 & 21528 & 21633 & 21775 \\
\hline Anchor padeye depth [m] & $\mathrm{za}_{\mathrm{a}}$ & 9.58 & 7.81 & 8.61 & 9.32 & 9.96 & 10.56 & 11.12 & 11.65 & 12.16 & 12.65 \\
\hline Padeye location [\%] & $r_{z}$ & $57.6 \%$ & $56.8 \%$ & $57.2 \%$ & $57.5 \%$ & $57.7 \%$ & $57.9 \%$ & $58.1 \%$ & $58.3 \%$ & $58.5 \%$ & $58.6 \%$ \\
\hline Angle at the padeye [deg] & $\theta_{a}$ & 13.90 & 12.12 & 12.93 & 13.64 & 14.28 & 14.87 & 15.41 & 15.93 & 16.42 & 16.90 \\
\hline Tension at the padeye (variable) [kN] & $\mathrm{T}_{\mathrm{a}}$ & 21740 & 21910 & 21833 & 21765 & 21705 & 21649 & 21598 & 21549 & 21503 & 21458 \\
\hline Horizontal load on the anchor $[\mathrm{kN}]$ & $\mathrm{H}_{\mathrm{a}}$ & 21103 & 21421 & 21279 & 21151 & 21034 & 20925 & 20821 & 20722 & 20625 & 20531 \\
\hline Vertical load on the anchor [kN] & $V_{a}$ & 5224 & 4601 & 4885 & 5133 & 5353 & 5554 & 5740 & 5914 & 6079 & 6237 \\
\hline Horizontal load check exponent [-] & a & 3.7 & 2.5 & 3 & 3.5 & 4 & 4.5 & 5 & 5.5 & 6 & 6.5 \\
\hline Vertical load check exponent [-] & $\mathrm{b}$ & 5.57 & 5.17 & 5.33 & 5.50 & 5.67 & 5.83 & 6.00 & 6.17 & 6.33 & 6.50 \\
\hline Horizontal utilisation [-] & $\mathrm{V}_{\mathrm{a}} / \mathrm{V}_{\max }$ & 0.585 & 0.425 & 0.497 & 0.562 & 0.62 & 0.672 & 0.72 & 0.764 & 0.803 & 0.838 \\
\hline Vertical utilisation [-] & $\mathrm{H}_{\mathrm{a}} / \mathrm{H}_{\max }$ & 0.986 & 0.995 & 0.992 & 0.988 & 0.983 & 0.977 & 0.97 & 0.963 & 0.953 & 0.943 \\
\hline
\end{tabular}


Table 5. Minimum caisson dimensions for various length to diameter ratios - medium sand.

\begin{tabular}{|c|c|c|c|c|c|c|c|c|c|c|c|}
\hline Length-to-diameter ratio of caisson & L/D [-] & 3.2 & 2 & 2.5 & 3 & 3.5 & 4 & 4.5 & 5 & 5.5 & 6 \\
\hline Minimum required caisson diameter [m] & $D_{\min }$ & 6.90 & 7.35 & 7.16 & 7.15 & 6.78 & 6.58 & 6.38 & 6.18 & 5.98 & 5.79 \\
\hline Corresponding length [m] & $L_{\min }$ & 22.07 & 14.70 & 17.91 & 21.46 & 23.73 & 26.32 & 28.71 & 30.90 & 32.90 & 34.73 \\
\hline Wall thickness [m] & $t_{w}$ & 0.099 & 0.105 & 0.102 & 0.102 & 0.097 & 0.094 & 0.091 & 0.088 & 0.085 & 0.083 \\
\hline \multirow[t]{3}{*}{ Effective weight of the caisson $[\mathrm{kN}]$} & $W_{c}$ & 3361 & 2652 & 3002 & 3529 & 3468 & 3594 & 3659 & 3674 & 3650 & 3594 \\
\hline & $(\mathrm{K} \tan \delta) \mathrm{o}$ & 7.00 & 7.00 & 7.00 & 7.00 & 7.00 & 7.00 & 7.00 & 7.00 & 7.00 & 7.00 \\
\hline & $(\mathrm{K} \tan \delta) \mathrm{i}$ & 5.00 & 5.00 & 5.00 & 5.00 & 5.00 & 5.00 & 5.00 & 5.00 & 5.00 & 5.00 \\
\hline External shaft friction [kN] & $\mathrm{Fe}_{\mathrm{e}}$ & 7343 & 5512 & 6407 & 7668 & 7634 & 7987 & 8194 & 8280 & 8266 & 8174 \\
\hline Internal shaft friction [kN] & $\mathrm{Fi}_{\mathrm{i}}$ & 6901 & 5168 & 6015 & 7204 & 7177 & 7513 & 7711 & 7793 & 7782 & 7697 \\
\hline Maximum vertical load capacity $[\mathrm{kN}]$ & $\mathrm{V}_{\max }$ & 14247 & 10682 & 12425 & 14875 & 14814 & 15503 & 15909 & 16077 & 16052 & 15875 \\
\hline Maximum horizontal load capacity [kN] & $\mathrm{H}_{\max }$ & 278358 & 131492 & 190360 & 272710 & 316219 & 377625 & 435429 & 488462 & 536069 & 577996 \\
\hline Anchor padeye depth [m] & $\mathrm{za}$ & 14.72 & 9.80 & 11.94 & 14.31 & 15.82 & 17.55 & 19.14 & 20.60 & 21.93 & 23.15 \\
\hline Padeye location [\%] & $\mathrm{r}_{\mathrm{z}}$ & 0.67 & 0.67 & 0.67 & 0.67 & 0.67 & 0.67 & 0.67 & 0.67 & 0.67 & 0.67 \\
\hline Angle at the padeye [deg] & $\theta_{a}$ & 50.14 & 32.10 & 39.77 & 67.81 & 54.40 & 61.25 & 67.76 & 73.91 & 79.70 & 85.13 \\
\hline Tension at the padeye (variable) $[\mathrm{kN}]$ & $\mathrm{T}_{\mathrm{a}}$ & 18561 & 20081 & 19420 & 16065 & 18219 & 17682 & 17187 & 16732 & 16315 & 15933 \\
\hline Angle at the padeye [deg] & $\mathrm{H}_{\mathrm{a}}$ & 11897 & 17012 & 14926 & 6068 & 10605 & 8504 & 6505 & 4638 & 2918 & 1353 \\
\hline Tension at the padeye (variable) [kN] & $V_{a}$ & 14247 & 10670 & 12424 & 14875 & 14814 & 15503 & 15909 & 16077 & 16052 & 15875 \\
\hline Horizontal load on the anchor [kN] & $\mathrm{a}$ & 3.7 & 2.5 & 3 & 3.5 & 4 & 4.5 & 5 & 5.5 & 6 & 6.5 \\
\hline Vertical load on the anchor [kN] & $\mathrm{b}$ & 5.5667 & 5.1667 & 5.3333 & 5.5 & 5.6667 & 5.8333 & 6 & 6.1667 & 6.3333 & 6.5 \\
\hline Horizontal utilisation [-] & $\mathrm{V}_{\mathrm{a}} / \mathrm{V}_{\max }$ & 1.00 & 1.00 & 1.00 & 1.00 & 1.00 & 1.00 & 1.00 & 1.00 & 1.00 & 1.00 \\
\hline Vertical utilisation [-] & $\mathrm{H}_{\mathrm{a}} / \mathrm{H}_{\max }$ & 0.04 & 0.13 & 0.08 & 0.02 & 0.03 & 0.02 & 0.01 & 0.01 & 0.01 & 0.00 \\
\hline
\end{tabular}




\subsection{Conclusions}

This paper presents a very simple methodology to obtain the loads on anchors for a floating offshore wind turbine. The loads derived are calculated for the floating spar-mooring line connection point and then conservatively transferred to the anchor through an inverse catenary. It has been shown that the actual anchor load estimated is conservative due to fact that the load taken by the weight of the mooring line and the forerunner, as well as the friction of the horizontal section (touchdown zone) on the seabed is ignored in the analysis. However, the values obtained here are upper bound estimates for the actual ultimate load expected, and therefore can be considered conservative and may be used for tender design and feasibility studies. The methodology may be further improved and some conservatism relieved by taking a dynamic approach. The example of the first floating turbine (Hywind) is taken to show the application of the formulation whereby the anchor loads are calculated. The values obtained by the proposed methodology are similar to those estimated for the planned floating wind farm. A simple approach is also presented for estimating the minimum size of the caisson for various length to diameter aspect ratios. The estimated foundation size is shown to be reasonably close to the preliminary conservative upper bound estimations for the Hywind floating offshore wind turbine structures. The approach presented can be used as a quick method for conservative conceptual design.

\section{References}

Arany, L., Bhattacharya, S., Macdonald, J., \& Hogan, S. J. (2017). Design of monopiles for offshore wind turbines in 10 steps. Soil Dynamics and Earthquake Engineering, 92, 126-152

Arany L, Bhattacharya S, Macdonald J, Hogan SJ (2015) Simplified critical mudline bending moment spectra of offshore wind turbine support structures. Wind Energy 18:2171-2197. doi: 10.1002/we.1812

DNV (2014) Offshore Standard DNV-OS-J101 Design of Offshore Wind Turbine Structures. Høvik, Norway

DNV (2013) Offshore Standard DNV-OS-J103 - Design of Floating Wind Turbine Structures.

DNV (1992) Classification Note 30.4 Foundations. 54.

DNV GL (2016) DNVGL-ST-0437 Loads and site conditions for wind turbines.

DNV GL (2017) DNVGL-RP-E301 - Design and installation of fluke anchors.

edp (2012) The WindFloat Project.

European Wind Energy Association (2013) Deep water - The next step for offshore wind energy.

Frohboese P, Schmuck C (2010) Thrust coefficients used for estimation of wake effects for fatigue load calculation. Eur. Wind Energy Conf. 2010, Warsaw, Pol. pp 1-10

George J (2014) WindFloat design for different turbine sizes.

Henderson AR, Leutz R, Fujii T (2002) Potential for Floating Offshore Wind Energy in Japanese Waters. 3:505-512.

Ho A, Mbistrova A, Corbetta G (2016) The European Offshore Wind Industry: Key Trends and Statistics 2015. Brussels, Belgium

Houlsby G, Kelly R, Byrne B (2005a) The tensile capacity of suction caissons in sand under rapid loading. Front Offshore Geotech 405-410. doi: 10.1201/NOE0415390637.ch40

Houlsby GT, Ibsen LB, Byrne BW (2005b) Suction caissons for wind turbines. In: Gourvenec, Cassidy (eds) Front. Offshore Geotech. ISFOG 2005 - Gourvenec Cassidy. Taylor \& Francis Group, London, UK, pp 75-94

Jonkman J (2007) Dynamics Modeling and Loads Analysis of an Offshore Floating Wind Turbine Introduction Background - The Big Picture.

Miedema SA, Lagers GHG, Kerkvliet J (2007) An overview of drag embedded anchor holding capacity for dredging and offshore applications. In: Randall REP (ed) Proc. 18th World Dredg. Congr. 
(WODCON XVIII). Newman Printing Company, Lake Buena Vista, FL, USA, pp 245-274

Myhr A, Bjerkseter C, Agotnes A, Nygaard TA (2014) Levelised cost of energy for offshore floating wind turbines in a life cycle perspective. Renew Energy 66:714-728. doi:

10.1016/j.renene.2014.01.017

Nielsen FG, Hanson TD, Skaare B (2006) Integrated Dynamic Analysis of Floating Offshore Wind Turbines. Proc 25th Int Conf Offshore Mech Arct Eng. doi: 10.1115/OMAE2006-92291

Principle Power I (2010) WindFloat Offshore Wind Power Plant.

Randolph M, Gourvenec MRS (2011) Offshore Geotechnical Engineering. Spon Press (Taylor \& Francis), New York, USA

Senders M, Kay S (2002) Geotechnical suction pile anchor design in deep water soft clays. Conf.

Deep. Risers Mooring Anchorings, London

Statoil (2015) Hywind Scotland Pilot Park - Executive Summary of the Environmental Statement. 